\title{
Article
}

\section{Dynamic Linkages among Saudi Market Sectors Indices}

\author{
Farouq Altahtamouni *, Hajar Masfer (D) and Shikhah Alyousef
}

\author{
Financial Sciences Department, Applied College, Imam Abdulrahman Bin Faisal University, P.O. Box 1982, \\ Dammam 31441, Saudi Arabia; hmmasfer@iau.edu.sa (H.M.); salyousef@iau.edu.sa (S.A.) \\ * Correspondence: fraltahtamouni@iau.edu.sa
}

Citation: Altahtamouni, Farouq, Hajar Masfer, and Shikhah Alyousef. 2022. Dynamic Linkages among Saudi Market Sectors Indices. Economies 10: 16. https://doi.org/ 10.3390/economies10010016

Academic Editor: Robert Czudaj

Received: 28 October 2021

Accepted: 28 December 2021

Published: 4 January 2022

Publisher's Note: MDPI stays neutral with regard to jurisdictional claims in published maps and institutional affiliations.

Copyright: (C) 2022 by the authors. Licensee MDPI, Basel, Switzerland. This article is an open access article distributed under the terms and conditions of the Creative Commons Attribution (CC BY) license (https:// creativecommons.org/licenses/by/ $4.0 /)$.

\begin{abstract}
This study aims to test the causal relationship between Saudi stock market index (TASI) and sectoral indices throughout the period from 2016-2020. The study data were extracted through the main index of the Saudi market and the indices of the available data of 19 sectors out of 21 sectors. The unit root test was used along with the Granger causality test, in addition to multiple regression tests in order to analyze the study hypotheses. The study shows that all index series were stationary at the zero level I (0), and the results also show that there were bidirectional and unidirectional causal relationships between TASI and sectoral indices, and that TASI effectively mirrors all the changes that occur in the Saudi stock market.
\end{abstract}

Keywords: TASI; unit root; granger causality; sectoral indices

\section{Introduction}

In developed and emerging economies, a stock market is one of the fundamental pillars playing active roles in that development, for it acts as an intermediary between borrowers and lenders. An efficient stock market refers to how successful a market is in incorporating stock prices, which reflect the stock value (Keane 1983). This market may accelerate the development process in an economy through raising savings and efficient allocation of resources.

Throughout recent years, stock market integration has become a major topic in finance literature and has gained wide currency due to its high significance for many parties involved (Youcef and Adewale 2017). This integration could generate considerable economic growth across the economy, enhance the allocation of capital, decrease costs of capital, and raise the risk sharing efficiency.

On the contrary, Rehman and Hazazi (2014) explain that this co-movement among economies may increase homogeneity in market performance in reaction to international financial impacts. This might cause a peril from some events such as a credit crunch, capital flight, a contagion effect, and so on.

Accordingly, the transmission of volatility and crises among different sectors of a stock market is an important issue for policy makers, investors and researchers (Mohammed et al. 2020; Ahmed 2016).

There is a significant concern with studies considering the relationship between the general stock market index and the sector indices. For example, Sharabati et al. (2013) and Aravind (2017) illustrate that there is a strong tendency for stock prices to move in accordance with the overall stock market and in parallel with the direction of other stocks in the same sector. Besides, the movement of stock prices in one sector may affect stock prices in another sector. Whenever a company has a large market capitalization, many changes might occur in other stock prices in the same sector (Sharabati et al. 2013). Thus, understanding and examining the relationship between various sectors' indices on one hand and the general index on the other would greatly benefit all parties involved.

Over the last three decades, emerging markets have raised profits enormously, for they provide many investment opportunities in financial sectors (Rehman and Hazazi 2014). 
Saudi Arabia, which is considered as the biggest oil exporter country in the world, has one of the strongest stock markets among the Gulf Council Countries (GCC), the Middle East, and North Africa (MENA) (Mustafa 2012). The Saudi stock market (Tadawul) was formally established in 1984, and it is now one of the leading emerging markets in the Arab world. Then, in 2001, and as a result of the rising of the trading volume in Saudi stock, a new official Saudi stock market index called TASI was established (Tadawul All Share Index) (Tadawul 2019). Additionally, the extant statistic reports of Tadawul (2019) mentioned that the number of companies listed on the stock exchange increased from 163 in 2013 to 199 at the end of 2019, with total market capitalization of US\$2,406.78 billion.

In this context, through conducting the Granger causality between this market's indices, the investigation on the Saudi Arabia's stock market (Tadawul) would contribute to clarifying the volatility of Tadawul.

\section{Study Objectives}

This study aims at:

1. Testing the causal relationship between the Saudi market index returns and sectoral indices returns.

2. Measuring the efficiency of the TASI in reflecting all changes in the market; measuring whether the index is designed in a way that reflects changes in the market or not.

\section{The Importance of the Study}

This study adds new information about a developing market such as the Saudi market, which has proven its worth during the previous years as one of the most important markets globally and in the Middle East, especially as it includes the Aramco company which is considered the largest company in the world in terms of market value. Since the Kingdom of Saudi Arabia is considered one of the Group of Twenty countries (G 20), meaning that it is one of the largest economies in the world, and this makes this study of great importance. Finally, this study is considered important because it is the first study that aims to examine the relationships between the Saudi market index (TASI) and sectoral indices, and through its results, this study attempts to provide a service to investors that helps them make their investment decisions.

\section{Literature Review}

The co-movement among sectors of the equity exchange and the extent of its impact on the general index of the market have long been the subject of researcher attention. Scholars use different research methods and statistics to analyze and understand this relationship. Many use Pearson's correlation method to investigate the relationship between one sector and others in the market (Rajamohan and Muthukamu 2014) or to investigate the linkage among all industries within a market (Mohanty et al. 2019; Cao et al. 2013). Other researchers employ Granger causality to test the effect of industry indices (Mustafa 2012; Ahmed 2016; Aravind 2017). In addition, some studies use ANOVA to analyze the variation among sectoral indices (Sharabati et al. 2013), while others use Vector Error Correction Model (Arbrlaez et al. 2001; Vardhan et al. 2015). Furthermore, Sharabati et al. (2013) employed Johansen's multivariate cointegration analysis to study the abovementioned correlation.

The findings of these studies share some points and differ in others. For instance, Rajamohan and Muthukamu (2014) examined the relationship between the banking industry index and other sectors in the National Stock Exchange of India and found a direct link between the banking industry and other sectors in the market. This result is consistent with Vardhan et al. (2015), who concluded that the banking industry is a leading industry in the Indian Stock Market. Moreover, some studies dealt with the long/short-term relationship like Mustafa (2012), which investigates the co-movement of the Saudi stock market sub-sectors and their connection with the whole market. Considering this to be a long-term relationship, unlike a short-term relationship, there seems to be a positive 
correlation among Saudi sub-sectors indices. There is also a long-term causality between the sub-sectors and the market portfolio's movement. Similarity, Ahmed (2016) comes to the same conclusion on the Egyptian Stock Exchange and Arbrlaez et al. (2001) did so in their analysis of the Colombian Stock Exchange. Furthermore, there are several research findings about the significance of this connection that vary by sector. By way of illustration, Mohanty et al. (2019) found that all industries in the Bombay stock Market have a positive influence on the market index, except for health care and telecommunications. The health index has an inverse correlation with all other sectors. Yet, the telecommunications industry is directly correlated with the automotive and health sectoral indices, and it is inversely related to the indices for information technology, banks, fast-moving consumer goods, and oil. Likewise, Aravind (2017) demonstrated a unidirectional linkage among the Indian Stock Exchange index, FMCG and IT. However, the banking industry shows a highly significant correlation to the market index. On the other hand, Sharabati et al. (2013) analyzed the data of the Jordanian Stock Exchange to determine the correlations among sectoral indices and the market overall. They found a remarkable positive correlation among the sectors in the long run, especially in the sectors of finance, industry and services respectively. Another study examined the sectoral behavior of the Chinese Stock Market index and divides it into two periods based on economic conditions (Cao et al. 2013). The first occurs when the market experiences a sharp rise and fall in stock prices and sectoral indices show consistent behavior together. The other takes place when the market is in a normal condition, and the findings vary depending on the industry. Some industries indices show strong linkage to the market portfolio, including financial services, energy, and industrials. Nevertheless, some show a weak linkage to the market, such as telecom, IT, and utilities. In addition, some industries show no linkage to the market, such as health, consumer discretionary, and consumer staples (Cao et al. 2013).

Arbrlaez et al. (2001) found that the co-movement among sectoral indices is becoming more significant over time and suggest that this conclusion could be applicable in other emerging markets. There are some studies that examine not only the relationship between market indicators but also between different market indices. The most recent study on this subject is a study of Joshi et al. (2021), where researchers aimed to examine the degree of interdependence between 22 indices in the American and European regions from 2005 to 2018 by using ADF and a causality test. The results indicate that there is a significant amount of interdependence between stock markets. It was also observed that there is an association between markets. Stoupos and Kiohos (2021) tested, through their studies, the integration between the European area stock markets after the end of 2010 debt crisis. The results revealed that the stock market integration was strong between Germany and EA core member-states, but disparate for the EA periphery. In contrast, there are only indications regarding the EA, Eastern Mediterranean and Baltic stock markets' integration with the DAX-30. And there is the Kapar et al. (2020) study, which is one of the studies that examined the integration of financial markets using data from the Dubai Financial Market Stock Exchange, the Abu Dhabi Stock Exchange and the FTSE Nasdaq Dubai UAE 20 index, by applying a vector error correction model and a permanent-transitory decomposition to the series of prices. The researchers found a long-run equilibrium relationship between the three financial indices, suggesting that UAE stock markets are integrated, and they found that shocks to any of these markets affect the other markets in the long and the short run through the equilibrium condition. Furthermore, Nasser and Hajilee (2016) examined stock market integration among five selected emerging stock markets (Brazil, China, Mexico, Russia and Turkey) and the developed markets of the US, UK and Germany by using monthly data from 2001 to 2014. The results show evidence of the existence of short-run integration among stock markets in emerging countries and developed markets, and the long-run coefficients for stock market returns in all emerging countries showed a significant relationship only with Germany's stock market return. Therefore, our study enriches the preceding literature with an up-to-date time series analysis for the Saudi Stock Exchange 
(Tadawul). Moreover, it will appeal to investors and portfolio managers by presenting the effectiveness of portfolio diversification in the Saudi equity market.

\section{Research Methodology}

\subsection{Sample and Data}

The study sample consists of daily data for the Saudi Stock Market General Index (TASI: Tadawul All Share Index) and 21 sectoral indices from 2016-2020. The study relies on 19 sectors in order to provide data for the indicators of these sectors, as shown in Table 1.

Table 1. Indices and index symbols.

\begin{tabular}{|c|c|c|c|c|c|}
\hline Index & $\begin{array}{c}\text { Index } \\
\text { Symbol * }\end{array}$ & Index & $\begin{array}{c}\text { Index } \\
\text { Symbol * }\end{array}$ & Index & $\begin{array}{c}\text { Index } \\
\text { Symbol * }\end{array}$ \\
\hline $\begin{array}{l}\text { General } \\
\text { Index }\end{array}$ & TASI & Capital Goods & CG & Energy & EN \\
\hline Materials & MAT & $\begin{array}{l}\text { Commercial and } \\
\text { Professional Svc }\end{array}$ & CandPS & Transportation & TR \\
\hline $\begin{array}{c}\text { Consumer } \\
\text { Durables and } \\
\text { Apparel }\end{array}$ & CDandA & $\begin{array}{l}\text { Consumer } \\
\text { Services }\end{array}$ & CS & $\begin{array}{c}\text { Media and } \\
\text { Entertainment }\end{array}$ & MandE \\
\hline Retailing & RE & $\begin{array}{l}\text { Food and Staples } \\
\text { Retailing }\end{array}$ & FandSR & $\begin{array}{l}\text { Food and } \\
\text { Beverages }\end{array}$ & FandB \\
\hline $\begin{array}{c}\text { Health Care } \\
\text { Equipment } \\
\text { and Svc }\end{array}$ & HCEandS & $\begin{array}{l}\text { Pharma, Biotech } \\
\text { and Life Science }\end{array}$ & PBandLS & $\begin{array}{l}\text { Diversified } \\
\text { Financials }\end{array}$ & DF \\
\hline Insurance & IN & $\begin{array}{l}\text { Telecommunication } \\
\text { Services }\end{array}$ & TELE & Utilities & UTILI \\
\hline $\begin{array}{l}\text { Real Estate } \\
\text { Mgmt and } \\
\text { Dev't }\end{array}$ & REM & Banks & BNK & & \\
\hline
\end{tabular}

\subsection{The Study Hypotheses}

The hypotheses of the study were formulated according to the questions of the study and its goals in order to test the relations between the study variables.

\subsubsection{Hypotheses of the Time-Series Non-Stationarity Test}

Hypothesis 1 (H1). TASI returns are nonstationary or have a unit root.

Hypothesis 2 (H2). The sectoral indices returns are nonstationary or have a unit root.

5.2.2. Hypothesis Testing Causality between TASI and Sectoral Indices

Hypothesis 3 (H3). TASI returns do not cause sectoral returns.

Hypothesis 4 (H4). Sectoral indices returns do not cause TASI returns.

5.2.3. Hypothesis of the Multiple Regression

Hypothesis 5 (H5). The sectoral indices have no statistically significant effect on the TASI.

\subsection{Statistical Methods Used in the Study}

The following tests were used to examine the hypotheses of the study: 


\subsubsection{Tests of Nonstationarity (Unit Root Test)}

Most of the time series of macroeconomic variables are affected by an instability procedure and the presence of a unit root, and regression on a model that contains nonstationary time series will lead to a spurious skew among the data and cause problems in the analysis (Granger and Newbold 1974). Thus, it is not possible to use t-ratios to determine the effect of one variable on another variable in the event of nonstationarity. This is due to the presence of a trend factor which reflects certain conditions that affect all variables, making them change in the same direction despite the absence of a real relationship among them.

Therefore, most studies assume that the time series used in the analysis are stationary series. The stationarity of the time series means that the mean and variance of the series are stationary over time and that the covariance between two time periods depends on the time differences between those two periods (Lags) and not on the real value of time.

If the time series is stationary in its original form, then it is said to be integrated of the zero order I (0), and if it is nonstationary, the time differences must be taken for it until it becomes stationary. One important condition of the cointegration technique is to prove that the time series used in the cointegration model are integrated in the same order.

The nonstationary hypothesis in time series is usually tested by the Autocorrelation Function (ACF) test and the Unit Root Test, a test that examines the long-term statistical properties of variables.

One of the most important tests examining the unit root is the Augmented DickeyFuller (ADF) test (Engle and Granger 1987), which suggests the following equations:

With constant and without trend $\Delta Y_{t}=\alpha+\delta Y_{t}-1+\mu_{t}$

With constant and with trend $\Delta Y_{t}=\alpha+\alpha 1 T+\delta Y_{t}-1+\mu_{t}$

Where $Y_{t}=$ Index Time Series and $=$ Linear Trend.

The null hypothesis of both ADF tests is that a series is nonstationary; hence, rejection of the unit root hypothesis is necessary to support stationarity.

\subsubsection{Granger's Causality Test}

Before discussing the causal relationship test for time series, it is worth mentioning that this test shows the short-term relationship, unlike the cointegration relationship test, which shows the long-term relationship. It is also noteworthy that these series are stationary and integrated at the same level. (Granger 1986).

The mathematical equation to measure Granger causality depends on the linear regression model used in the prediction method. Granger's study (Granger 1969) is one of the most important studies demonstrating the concept of causality among variables.

To measure the causal relationship in the short term among the indicators, the following equations were used:

$$
\begin{aligned}
& Y_{t}=\sum_{i=1}^{n} \alpha_{i} Y_{t-i}+\sum_{j=1}^{n} \beta_{j} X_{t-j}+\mu_{1 t} \\
& X_{t}=\sum_{i=1}^{n} \lambda_{i} Y_{t-i}+\sum_{j=1}^{n} \sigma_{j} X_{t-j}+\mu_{2 t}
\end{aligned}
$$

The two equations postulate that the current values, $Y_{t}$ and $X_{t}$, are related to their past values, and vice versa. Unidirectional causality from $X_{t}$ and $Y_{t}$ is indicated if the estimated coefficients on the lagged $X_{t}$ are statistically different from zero as a group (i.e., $\Sigma \beta \neq 0$ ) and if the set of estimated coefficients on the lagged $Y_{t}$ are not statistically different from zero if $\Sigma \lambda \neq 0$. The converse is also the case for unidirectional causality from $\underline{Y_{t}}$ to $X_{t}$. Feedback or bilateral causality exists when the sets of $X_{t}$ and $Y_{t}$ coefficients are statistically different from zero in the above two regressions (Gujarati and Porter 2009). 


\subsubsection{Multiple Regression}

To test the efficiency of the market index in reflecting the changes that occur in the market, a multiple linear regression (MLR) test was employed, using the ordinary least squares (OLS) method.

\section{Results and Discussion}

\subsection{Descriptive Statistics}

Table 2 reveals the descriptive analysis of the indicators, which shows average mean returns, median, standard deviations, skewness, kurtosis, etc. The normal distribution of index returns was also tested through Jarque-Bera test. The table also shows that the highest average return is the sector index return for Media and Entertainment. Moreover, it can be seen through the table that the least-risk index, as measured by standard deviation, was TASI (0.009981), which means that the market's portfolio is well diversified compared to other sectors. When measuring normality of the indices in question, it was found that all indicators had normal distributions, as indicated by the test results. It is clear, too, that the probability values obtained for all return series in Jarque-Bera test were statistically significant at 5 percentage level of significance $(p$-values $0.00<0.05)$.

Table 2. Descriptive statistics.

\begin{tabular}{|c|c|c|c|c|c|c|c|c|c|}
\hline Index & Mean & Median & Maximum & Minimum & Std. Dev. & Skewness & Kurtosis & $\begin{array}{c}\text { Jarque- } \\
\text { Bera }\end{array}$ & Probability \\
\hline TASI & 0.000238 & 0.000440 & 0.054972 & 0.054422 & 0.009981 & -0.311909 & 7.151503 & 732.8700 & 0.000000 \\
\hline CG & $8.86 \times 10^{-5}$ & $-7.69 \times 10^{-5}$ & 0.054716 & -0.086279 & 0.013713 & -0.726962 & 8.244954 & 1231.842 & 0.000000 \\
\hline $\mathrm{EN}$ & 0.000116 & 0.000578 & 0.072099 & -0.083255 & 0.014795 & -0.714334 & 7.746601 & 1021.757 & 0.000000 \\
\hline MAT & 0.000217 & 0.000296 & 0.050145 & -0.062381 & 0.010805 & -0.349827 & 7.231947 & 765.0874 & 0.000000 \\
\hline CandPS & -0.000144 & 0.000000 & 0.055347 & -0.069565 & 0.013649 & -0.249655 & 6.929168 & 652.3456 & 0.000000 \\
\hline TR & $7.68 \times 10^{-5}$ & 0.000306 & 0.057756 & -0.086615 & 0.013475 & -0.735714 & 9.039188 & 1606.651 & 0.000000 \\
\hline CDandA & -0.000593 & $-8.68 \times 10^{-5}$ & 0.043514 & -0.095023 & 0.014641 & -1.349102 & 10.09367 & 2395.221 & 0.000000 \\
\hline CS & -0.000619 & -0.000272 & 0.066434 & -0.091661 & 0.016478 & -0.911762 & 9.135963 & 1703.889 & 0.000000 \\
\hline MandE & 0.000757 & -0.001718 & 0.099206 & -0.098877 & 0.029390 & 0.777676 & 6.359102 & 569.8035 & 0.000000 \\
\hline $\mathrm{RE}$ & 0.000140 & 0.000134 & 0.071843 & -0.076269 & 0.013546 & -0.17355 & 8.446517 & 1238.560 & 0.000000 \\
\hline FandSR & 0.000343 & $-1.69 \times 10^{-5}$ & 0.084456 & -0.088972 & 0.015347 & 0.028389 & 7.904852 & 1000.528 & 0.000000 \\
\hline FandB & $-8.69 \times 10^{-5}$ & -0.000173 & 0.076047 & -0.081846 & 0.013921 & -0.071664 & 8.906486 & 1451.554 & 0.000000 \\
\hline HCEandS & $-9.79 \times 10^{-5}$ & -0.0001 & 0.069805 & -0.081724 & 0.012846 & -0.333837 & 9.002763 & 1516.916 & 0.000000 \\
\hline PBandLS & $-8.46 \times 10^{-5}$ & 0.000000 & 0.086726 & -0.102517 & 0.016015 & -0.01494 & 9.699236 & 1866.287 & 0.000000 \\
\hline $\mathrm{DF}$ & -0.00059 & -0.000437 & 0.070574 & -0.100569 & 0.013001 & -1.078841 & 13.53953 & 4812.740 & 0.000000 \\
\hline IN & $5.75 \times 10^{-5}$ & 0.000336 & 0.072648 & -0.081483 & 0.014091 & -0.769165 & 8.041647 & 1155.379 & 0.000000 \\
\hline TELE & 0.000326 & 0.000283 & 0.053508 & -0.070404 & 0.012824 & -0.301258 & 6.318935 & 473.1499 & 0.000000 \\
\hline UTILI & 0.000369 & 0.000000 & 0.094274 & -0.09476 & 0.015362 & -0.061654 & 8.880617 & 1438.653 & 0.000000 \\
\hline REM & -0.000201 & -0.000448 & 0.054568 & -0.066644 & 0.012596 & -0.048861 & 6.186437 & 422.6086 & 0.000000 \\
\hline BNK & 0.000543 & 0.000408 & 0.080170 & -0.046349 & 0.011483 & 0.207672 & 7.277784 & 768.1249 & 0.000000 \\
\hline
\end{tabular}

\subsection{Results of Stationarity Test (Unit Root Test)}

Table 3 shows the results of the stationarity test of the indices returns after applying the Augmented Dickey-Fuller test. The results indicate that all indices were stationary with the presence of the constant in the equation and with the presence of the constant and linear trends. Consequently, it can be said that the indices are individually integrated to order zero (I (0)), which means that any of sectoral indices can be used to predict another. Thus, it is possible to reject the null Hypothesis H1, which states that the TASI returns are nonstationary. 
Table 3. Result of stationarity test.

\begin{tabular}{|c|c|c|}
\hline \multirow{3}{*}{ Name of the Series } & ADF & ADF \\
\hline & (with Constant) & (with Constant and Trend) \\
\hline & at Level & at Level \\
\hline TASI & $-26.39654 *$ & -26.38604 * \\
\hline CG & $-26.80089 *$ & $-26.78981 *$ \\
\hline EN & $-30.70559 *$ & $-30.73192 *$ \\
\hline MAT & -28.29010 * & -28.28174 * \\
\hline CandPS & -29.03020 * & $-29.07163 *$ \\
\hline TR & -26.96494 * & -26.96804 * \\
\hline CDandA & $-27.60776 *$ & $-27.63174 *$ \\
\hline CS & $-27.23331 *$ & $-27.35681 *$ \\
\hline MandE & -28.26591 * & $-28.25209 *$ \\
\hline RE & -25.17888 * & -25.22963 * \\
\hline FandSR & $-28.43957 *$ & $-28.42857 *$ \\
\hline FandB & $-27.19563 *$ & $-27.18508 *$ \\
\hline HCEandS & $-26.93679 *$ & -26.92953 * \\
\hline PBandLS & $-31.84689 *$ & $-31.83352 *$ \\
\hline DF & -28.30031 * & -28.31324 * \\
\hline IN & $-27.88356^{*}$ & $-27.87063 *$ \\
\hline TELE & $-26.87180 *$ & $-26.88294 *$ \\
\hline UTILI & $-28.72282 *$ & $-28.71862 *$ \\
\hline REM & $-26.88922 *$ & $-26.88876 *$ \\
\hline BNK & $-27.68039 *$ & -27.67806 * \\
\hline
\end{tabular}

* Significant at $1 \%$.

\subsection{Results of Causality Test}

Table 4 indicates that, when applying the Granger causality test, it can be concluded that the general Saudi market index (TASI) affects 10 sectoral indices out of the 19 indices of the study sample. This indicates that the TASI return can be used to predict the returns of the sectoral indices that move along with the movements of the TASI, and those indices are: energy, materials, commercial and Professional svc, consumer durables and apparel, retailing, food and staples retailing, food and beverages, pharma, biotech and life science, insurance, and banks. It can also be noted that there are only two indices whose movements affect TASI, transportation and pharma, biotech and life science. The only index that both affects and is affected by the general index is pharma, biotech and life science. Those results indicate that the null Hypothesis $\mathrm{H} 3$ can be rejected, which states that TASI returns do not cause sectoral returns. These results also indicate that the null Hypothesis $\mathrm{H} 4$ can be rejected, which states that sectoral index returns do not cause TASI returns.

Table 5 indicates that the most influential index among the rest of the sectoral indices was the transportation sector index, which affects 17 sectors, while the least influential index was the media and entertainment sector index, which affects one sector. Moreover, Table 5 shows that the most affected index is the insurance sector index, which is affected by 16 sectors, and the least affected index is the services sector index, which is affected by only one sector.

These results indicate that we can use some series of index returns to predict the return values of other indices, which supports the assumption that there are investment risks in the financial portfolios and reduces the importance of diversifying financial portfolios. 
Table 4. Granger causality test between TASI and sectoral indices.

\begin{tabular}{|c|c|c|c|c|c|c|}
\hline Null Hypothesis & F-Statistics & Hypothesis Testing & Null Hypothesis & F-Statistics & Hypothesis Testing & Causality Direction \\
\hline TASI does not Granger Cause CG & 1.89333 & H3: Fail to reject & CG does not Granger Cause TASI & 0.70508 & H4: Fail to reject & $\mathrm{TASI} \leftarrow / / \rightarrow \mathrm{CG}$ \\
\hline TASI does not Granger Cause EN & $4.56227 *$ & H3: Reject & EN does not Granger Cause TASI & 0.97897 & H4: Fail to reject & $\mathrm{TASI} \rightarrow \mathrm{EN}$ \\
\hline TASI does not Granger Cause MAT & $2.46887^{* * *}$ & H3: Reject & MAT does not Granger Cause TASI & 0.9711 & H4: Fail to reject & $\mathrm{TASI} \rightarrow \mathrm{MAT}$ \\
\hline TASI does not Granger Cause TR & 0.80063 & H3: Fail to reject & TR does not Granger Cause TASI & $2.55663^{* * *}$ & H4: Reject & $\mathrm{TASI} \leftarrow \mathrm{TR}$ \\
\hline $\begin{array}{c}\text { TASI does not Granger Cause } \\
\text { CDandA }\end{array}$ & 5.13947 * & H3: Reject & CDandA does not Granger Cause TASI & 1.8705 & H4: Fail to reject & TASI $\rightarrow$ CDandA \\
\hline TASI does not Granger Cause CS & 2.05215 & H3: Fail to reject & CS does not Granger Cause TASI & 1.61619 & H4: Fail to reject & $\mathrm{TASI} \leftarrow / / \rightarrow \mathrm{CS}$ \\
\hline TASI does not Granger Cause RE & $5.95202 *$ & H3: Reject & RE does not Granger Cause TASI & 0.71494 & H4: Fail to reject & $\mathrm{TASI} \rightarrow \mathrm{RE}$ \\
\hline TASI does not Granger Cause FandSR & $2.89666^{* * *}$ & H3: Reject & FandSR does not Granger Cause TASI & 1.56497 & H4: Fail to reject & TASI $\rightarrow$ FandSR \\
\hline TASI does not Granger Cause FandB & $7.88997 *$ & H3: Reject & FandB does not Granger Cause TASI & 0.30701 & H4: Fail to reject & TASI $\rightarrow$ FandB \\
\hline $\begin{array}{c}\text { TASI does not Granger Cause } \\
\text { HCEandS }\end{array}$ & 0.70316 & H3: Fail to reject & HCEandS does not Granger Cause TASI & 0.44913 & H4: Fail to reject & $\mathrm{TASI} \leftarrow / / \rightarrow \mathrm{HCEandS}$ \\
\hline $\begin{array}{c}\text { TASI does not Granger Cause } \\
\text { PBandLS }\end{array}$ & $3.65216^{* *}$ & H3: Reject & PBandLS does not Granger Cause TASI & $4.84799 *$ & H4: Reject & TASI $\leftarrow \rightarrow$ PBandLS \\
\hline TASI does not Granger Cause DF & 0.5626 & H3: Fail to reject & DF does not Granger Cause TASI & 1.50465 & H4: Fail to reject & $\mathrm{TASI} \leftarrow / / \rightarrow \mathrm{DF}$ \\
\hline TASI does not Granger Cause IN & $10.4520 *$ & H3: Reject & IN does not Granger Cause TASI & 1.1635 & H4: Fail to reject & $\mathrm{TASI} \rightarrow \mathrm{IN}$ \\
\hline TASI does not Granger Cause UTILI & 1.2735 & H3: Fail to reject & UTILI does not Granger Cause TASI & 1.70785 & H4: Fail to reject & $\mathrm{TASI} \leftarrow / / \rightarrow \mathrm{UTILI}$ \\
\hline TASI does not Granger Cause REM & 1.48586 & H3: Fail to reject & REM does not Granger Cause TASI & 0.38582 & H4: Fail to reject & $\mathrm{TASI} \leftarrow / / \rightarrow \mathrm{REM}$ \\
\hline TASI does not Granger Cause BNK & $7.47603 *$ & H3: Reject & BNK does not Granger Cause TASI & 1.82353 & H4: Fail to reject & $\mathrm{TASI} \rightarrow \mathrm{BNK}$ \\
\hline
\end{tabular}

${ }^{*}$ Means that it is significant at $1 \%{ }^{* *}$ means it is significant at $5 \%,{ }^{* * *}$ means it is significant at $10 \% . \leftarrow \rightarrow$ bidirectional, $\rightarrow$ unidirectional, $\leftarrow / / \rightarrow$ There is no causal relationship. 
Table 5. Granger causality test between sectoral indices.

\begin{tabular}{|c|c|c|c|c|c|c|c|c|c|c|c|c|c|c|c|c|c|c|c|}
\hline ID $D$ & CG & EN & MAT & CandPS & TR & CDandA & CS & MandE & RE & FandSR & FandB & HCEandS & PBandLS & DF & IN & TELE & UTILI & REM & BNK \\
\hline CG & & 0.45648 & 1.48460 & 1.64998 & 0.20995 & 2.28020 & 0.98936 & 1.91771 & $4.09264^{* *}$ & $3.50111^{* *}$ & $3.47637^{* *}$ & 0.36481 & $2.63952^{* * *}$ & 0.97308 & $3.63531^{* *}$ & 1.52603 & 0.46496 & 0.73568 & $3.72477^{* *}$ \\
\hline $\mathrm{EN}$ & 2.22344 & & 0.77036 & 0.36671 & 0.56483 & $3.57709^{* *}$ & 1.49635 & 1.94669 & 2.20187 & $5.89044 *$ & $7.29349 *$ & 2.20773 & $12.3466^{*}$ & $3.14709 * *$ & $4.77162 *$ & $7.06109 *$ & 1.67844 & 0.12862 & $2.41638^{* * *}$ \\
\hline MAT & 0.34400 & $2.61606^{* * *}$ & & $2.96772 * *$ & 0.33173 & 1.69237 & 0.18539 & 1.44074 & $3.65460^{* *}$ & 0.78193 & $3.86979 * *$ & 0.20991 & 1.66046 & 0.04367 & $5.91230 * *$ & 1.08331 & 0.25988 & 0.80466 & $4.79116^{*}$ \\
\hline CandPS & $2.63571^{* * *}$ & $6.21266^{* *}$ & 0.30529 & & 1.05096 & $3.52352^{* *}$ & 0.92465 & $4.31836^{* *}$ & 1.45887 & $6.45613 *$ & $4.84766^{*}$ & $3.80464 * *$ & $6.10738^{*}$ & $2.95547^{* *}$ & $4.59283^{*}$ & $2.83624^{* * *}$ & 1.14745 & 0.83214 & 0.68246 \\
\hline CDandA & 1.44548 & 1.28390 & $2.33748^{* * *}$ & $3.61168^{* *}$ & 0.72483 & & 1.77269 & 2.06741 & $4.48125^{*}$ & $3.40628^{* *}$ & 0.20150 & 1.62787 & 2.36935 & 0.47006 & 0.88935 & 2.15193 & 1.49163 & $4.04055 * *$ & 1.64369 \\
\hline CS & 1.80188 & 1.83436 & 1.34144 & 2.08737 & 1.18200 & $8.83788^{*}$ & & $6.44778^{*}$ & $5.46203^{*}$ & 5.95831 * & $4.41416^{*}$ & 0.85118 & $5.38185^{*}$ & $4.10659^{* *}$ & $8.40325^{*}$ & 1.7 & 1.1 & 0.58021 & $5.86402 *$ \\
\hline MandE & 0.98207 & 0.39089 & 0.15299 & 0.88745 & 0.13565 & 1.05041 & 1.441 & & 0.88847 & 0.41594 & 0.2686 & 0.07854 & $2.66989^{* * *}$ & 0.19982 & 0.22625 & 1.62249 & 0.41645 & 0.64377 & 0.59019 \\
\hline RE & 0.21564 & $2.94480 * *$ & 0.24692 & 1.50073 & $3.29758^{* *}$ & $6.09736^{*}$ & $3.15777^{* *}$ & $6.13611 *$ & & 1.39713 & $2.37637 * * *$ & 0.01433 & $3.64740 * *$ & $2.61696^{* * *}$ & $4.27132 *$ & 1.62376 & 1.04112 & 1.16724 & $2.42417^{* * *}$ \\
\hline FandSR & 0.83146 & $2.59725^{* * *}$ & 1.16367 & 7500 & 0.22308 & $2.85825^{* *}$ & 1.65076 & 1.87439 & 0.59243 & & $4.09315^{* *}$ & 0.13374 & & 0.92592 & $2.89201^{* * *}$ & 1.72467 & 2.1 & 1.71141 & 1.09028 \\
\hline FandB & 1. & 0.34 & & 0. & 0.68059 & $6.17395 *$ & 0.79957 & 1 & 1.55711 & 1.9 & & 0.55695 & & & & & & & 3.94860 ** \\
\hline PBandLS & $6.63421 * *$ & 1.601 & $8.39918^{*}$ & 4.670 & 1.85 & 9.3 & 6.174 & & $4.43352 *$ & $33^{* *}$ & $2.77899 * * *$ & $6.88935^{*}$ & & $4.76455^{*}$ & & & & & $6.45582^{*}$ \\
\hline DF & 2.126 & 3.099 & 2.85 & 3.400 & $2.59846^{* * *}$ & 7.426 & 4.607 & & 8.24 & & 3.35 & 1.19 & $25 * *$ & & $7.95308^{*}$ & & & & $2.33067^{* * *}$ \\
\hline IN & 1.06907 & 0.185 & 0.66827 & 1.01680 & 1.07746 & 0.168 & 0.26836 & & 4.34 & & 1.720 & 0.00 & 3.32 & 0.08856 & & 0.62921 & 0.5 & 0.31205 & $2.57755^{* * *}$ \\
\hline TELE & 1.42282 & $2.95246^{* *}$ & $3.76718^{* *}$ & 1.3594 & 1.25798 & $2.78023 * *$ & 1.80026 & 0.65979 & $5.37455^{*}$ & $4.75656^{*}$ & 7.78107* & 0.79595 & 0.9 & 1.76622 & $5.41522 *$ & & 0.43629 & $2.37936^{* * *}$ & 2.04284 \\
\hline UTILI & & & & & & & 0.85 & & & & & $5^{* * *}$ & & $28^{* * *}$ & $5.84022 *$ & $3.99679 * *$ & & 4.72620 * & 282 \\
\hline REM & 2.01978 & $3.25918^{* *}$ & 2.01229 & $2.67992^{* * *}$ & 1.35442 & $3.32091^{* *}$ & 1.20972 & 0.73194 & 1.78848 & $3.06527^{* *}$ & $3.10933^{* *}$ & 0.93605 & $7.11331 *$ & 0.71372 & $5.98932 *$ & 1.85738 & $2.57013^{* * *}$ & & 1.81019 \\
\hline BNK & $2.62057^{* * *}$ & $3.56113^{* *}$ & 0.73719 & 2.12039 & 0.27232 & $3.38551^{* *}$ & 2.08882 & 2.02444 & $3.78023^{* *}$ & 1.11034 & $5.41075^{* * *}$ & 0.30352 & 1.87292 & 0.27527 & $5.70006 *$ & 1.37474 & 1.86040 & 1.57502 & \\
\hline
\end{tabular}

${ }^{*}$ Means that it is significant at $1 \%,{ }^{* *}$ means it is significant at $5 \%,{ }^{* * *}$ means it is significant at $10 \%$. 


\subsection{Results of Regression Analysis}

Table 6 shows the results of multiple linear regression test of TASI on sectoral indices. The results indicate the existence of a statistically significant effect of sectoral indices on TASI, and the model explains $99.75 \%$ of the changes in the market value. It was found through the results that all sectoral indices have a positive and statistically significant impact on TASI. This enhances the strength of the model for its adoption as an illustrative model for changes in TASI and indicates that TASI is an index that reflects all changes in TADAWUL.

Table 6. Results of multiple linear regression.

\begin{tabular}{cccc}
\hline Model & T & Sig. & $\begin{array}{c}\text { Collinearity } \\
\text { Statistics VIF }\end{array}$ \\
\hline (Constant) & -1.983369 & 0.0476 & \\
CG & 7.215750 & 0.0000 & 2.057 \\
EN & 10.29085 & 0.0000 & 1.748 \\
MAT & 91.34334 & 0.0000 & 2.863 \\
CandPS & 2.963960 & 0.0031 & 1.652 \\
TR & 2.492736 & 0.0128 & 2.257 \\
CDandA & 2.435842 & 0.0150 & 1.725 \\
CS & 7.491708 & 0.0000 & 1.787 \\
MandE & 2.931006 & 00.0035 & 1.174 \\
RE & 19.53803 & 0.0000 & 1.633 \\
FandSR & 4.967934 & 0.0000 & 1.368 \\
FandB & 32.37490 & 0.0000 & 1.703 \\
HCEandS & 5.563406 & 0.0000 & 1.820 \\
PBandLS & 3.595438 & 0.0003 & 1.431 \\
DF & 3.862521 & 0.0001 & 1.536 \\
IN & 17.60858 & 0.0000 & 1.812 \\
TELE & 32.44337 & 0.0000 & 1.657 \\
UTILI & 17.09430 & 0.0000 & 1.216 \\
REM & 47.40722 & 0.0000 & 1.646 \\
BNK & 174.2409 & 0.0000 & 2.305 \\
F-statistic & Prob (F-statistic $)$ & Adjusted & \\
21,670.13 & 0.0000 & $R$ Square & \\
\hline & & 0.997584 & \\
\hline
\end{tabular}

\section{Conclusions}

This study was based on testing the causal relationship between the TASI index of the Saudi stock market and determining whether the TASI is an effective tool for expressing the changes taking place in the market and in market sectors. This study attempted to draw conclusions that may help investors in the Saudi stock market (Tadawul) make efficient decisions about diversifying their investments and support their decisions about diversification efficiency. The Augmented Dickey- Fuller test (ADF) and the Granger causality test were used to test these relationships. The results showed that there is stationarity in these chains. The results also showed that there are bidirectional and unidirectional causal relationships between TASI and the sectoral indices. These results indicate the existence of short-term relationships among the indices comprising the Saudi stock market, and these results also show that there is no benefit of diversification. Moreover, the results of the regression analysis revealed that it is possible to rely on TASI to show the movement of Tadawul. These results confirm that the general index of the Saudi market (TASI) is a clear mirror of the changes taking place in sectors in the market. The results of the study were consistent with past findings (Rajamohan and Muthukamu 2014; Vardhan et al. 2015; Mustafa 2012; Ahmed 2016; Arbrlaez et al. 2001; Aravind 2017; Sharabati et al. 2013). We hope that researchers in the future will apply these techniques to studies of similar markets and compare the results of this study with the results from markets that operate in similar environment and conditions. 
Author Contributions: Conceptualization, F.A.; methodology, F.A.; software, F.A.; validation, F.A.; formal analysis, F.A.; investigation, F.A., H.M. and S.A.; resources, F.A., H.M. and S.A.; data curation, S.A.; writing—original draft preparation, F.A., H.M.; writing—review and editing, F.A.; visualization, F.A.; supervision, F.A.; project administration, F.A.; funding acquisition, self funding from F.A., H.M. and S.A. All authors have read and agreed to the published version of the manuscript.

Funding: This research received no external funding.

Data Availability Statement: The data are available from the authors upon request.

Conflicts of Interest: The authors declare no conflict of interest.

\section{References}

Ahmed, Walid. 2016. The Dynamic Linkages among Sector Indices: The Case of the Egyptian Stock Market. International Journal of Economics and Finance 8: 23-38.

Aravind, M. 2017. The Dynamic linkage among Sectoral Indices: Evidence from Indian Stock Market. Rajagiri Management Journal 11: 3-20.

Arbrlaez, Harvey, Jorge Urrutia, and Nidal Abbas. 2001. Short-Term and Long-Term Linkages Among The Colombian Capital Market Indexes. International Review of Financial Analysis 10: 237-73.

Cao, Dingmu, Wen Long, and Wenning Yan. 2013. Sector Indices Correlation Analysis in China's Stock Market. Information Technology and Quantitative Management 17: 1241-49.

Engle, Robert, and Clive W. J. Granger. 1987. Cointegration and Error Correction: Representation, Estimation and Testing. Econometrica 55: 251-76.

Granger, Clive William John, and Paul Newbold. 1974. Spurious Regressions in Econometrics. Journal of Econometrics 2: 111-20.

Granger, Clive William John. 1969. Investigating Causal Relations by Econometric Models and Cross Spectral Methods. Econometrica 37: 424-38.

Granger, Clive William John. 1986. Developments in the Study of Co-integrated Economic Variables. Oxford Bulletin of Economic and Statistics 48: 226-34.

Gujarati, Damodar, and Dawn Porter. 2009. Basic Econometrics, 5th ed. New York: McGraw-Hill/Irwin.

Joshi, Nisarg A., Dhyani Mehta, Bhavesh Patel, and Nikunj Patel. 2021. Causality and cointegration among stock market indices: A study of developed markets with sensex. International Journal of Accounting and Finance Review 7: 31-52.

Kapar, Burcu, Olmo Jose, and Ghalayini Rim. 2020. Financial Integration in the United Arab Emirates Stock Markets. Financial Research Letters 33: 101219.

Keane, Simon. 1983. Stock Market Efficiency: Theory, Evidence and Implications. Oxford: Philip Allan.

Mohammed, Sadouni, Mazeri Abdalhafid, and Boudjemel Ahmed. 2020. Examining Causal Relationship between Saudi Stock Market (TASI) and US Stock Markets Indices. Asian Journal of Economics, Finance and Management 2: 1-9.

Mohanty, Debasis, Mayadhar Satpathy, and Shakti Mohaptra. 2019. Impact of Sectoral Indices' Fluctuation on SENSEX. International Journal of Recent Technology and Engineering 8: 2603-8.

Mustafa, Makwan. 2012. Short-Run and Long-Run Dynamics Linkages among the Saudi Arabia Stock Market Indices. Prosiding Perkem 2: $1624-32$

Nasser, Omar, and Massomeh Hajilee. 2016. Integration of emerging stock markets with global stock markets. Research in International Business and Finance 36: 1-12.

Rajamohan, Selam, and Muthusamy Muthukamu. 2014. Bank Nifty Index and Other Sectoral Indices of NSE-A Comparitive Study. Indian Journal of Research 3: 147-49.

Rehman, Mohammed Ziaur, and Musa Ahmed Hazazi. 2014. Examining linkages between Saudi stock market (TASI) and selected stock markets indices. International Journal of Financial Research 5: 196-209.

Sharabati, Abdel-Aziz, Abdulnaser Noor, and Abdul Aziz Saymeh. 2013. The Relationship Between Amman Stock Exchange (ASE) Sector and (ASE) Generl Index Performance. European Journal of Accounting Auditing and Finance Research 1: 67-96.

Stoupos, Nikolaos, and Apostolos Kiohos. 2021. Euro area stock markets integration: Empirical evidence after the end of 2010 debt crisis. Finance Research Letters. (in press)

Tadawul. 2019. Annual Statistical Report (Main Market). Available online: https://annualreport2019.tadawul.com.sa/Resources/ AnnualReport2019/download/pdf/tadawul_2019.pdf (accessed on 27 October 2021)

Vardhan, Harsh, Pankaj Sinha, and Madhu Vij. 2015. Behavior of Indian Sectoral Stock Price Indices in The Post Subprime Crisis Period. Journal of Advances in Management Research 12: 15-29.

Youcef, Grimes, and Abideen Adewale. 2017. Dynamic Linkages Among SAMI Nations (Saudi Arabia, Turkey, Malaysia, Indonesia) Equity Markets. Journal of Islamic Finance 6: 014-034. 